\title{
Veteriner sahada güncel mikrobiyota kavramı
}

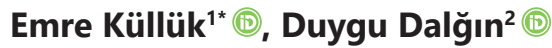 \\ 1,2 Ondokuz Mayıs Üniversitesi Veteriner Fakültesi, lç Hastalıkları Anabilim Dalı, Samsun, Türkiye
}

Geliş Tarihi / Received: 13.01.2020, Kabul Tarihi / Accepted: 05.04.2021

\begin{abstract}
Özet: Mikrobiyota; canlı vücudunda başlıca, gastrointestinal, deri, solunum, ürogenital sistemin hayati organlarında bulunan, bakteri, virus, mantar ve arkeleri ifade eder. Mikrobiyotanın genomu, canlı genomundan 1000 kat daha fazla gen dizilimi içerir. Mikrobiyotanın vücutta enerji metabolizması, hepatik fonksiyonlar, immün sistem gelişimi, motor sistem ve endokrin fonksiyonları üzerine etkileri vardır. Mikrobiyota kompozisyonu; diyet, antibiyotik kullanımı, stres gibi faktörlerden dolayı bozulabilmektedir ve mikrobiyotanın dengesinin bozulmasına "disbiyozis" denir. 2007 yılında daha sonraki araştırmalara ışık tutacak olan İnsan Mikrobiyom Projesi faaliyete geçirilmiş ve insan mikrobiyotasının özelliklerinin belirlenmesinde büyük önem taşımıştır. Çiftlik ve pet hayvanlarında yapılan çalışmalar henüz yenidir. Çiftlik hayvanlarında verim özelliklerinin artmasında, yemden yararlanmanın maksimum düzeyde tutulabilmesinde, süt yağının artışında mikrobiyotanın çok önemli bir rolü vardır. Pet hayvanlar, özellikle de köpekler ilk çağlardan beri insanoğluna eşlik edip, insanlarla hem yaşam alanını hem de mikrobiyotasını paylaşmaktadır. Evcil hayvan varlığının hem yetişkinler için, hem de özellikle yeni doğan çocukların mikrobiyota gelişiminde büyük bir rolü olduğu ve astım, alerjik rinit, atopik dermatit gibi alerjik hastalıkların görülme oranını azalttığı kanıtlanmıştır. Veteriner sahada mikrobiyota çalışmaları dünyada henüz son yıllarda çalışılmaya başlanmış olup, gün geçtikçe daha fazla araştırma yapılmaktadır ve hala araştııılmayı bekleyen birçok konu bulunmaktadır.
\end{abstract}

Anahtar kelimeler: Çiftlik hayvanları, kanatlı, mikrobiyota, pet, probiyotik

\section{Current microbiota concept in veterinary medicine}

\begin{abstract}
Microbiota refers to bacteria, viruses, fungi and archaea which are found in vital systems such as the gastrointestinal system, skin, respiratory system and urogenital system. The genome of the microbiota contains 1000 times more gene sequences than the organism genome. Microbiota has effects on energy metabolism, hepatic functions, immune system development, motor system and endocrine functions. Microbiota composition can break down by diet, use of antibiotics, stress, etc., and the disruption of this balance on microbiota is called "dysbiosis". In 2007, the Human Microbiology Project activity, which will shed light on further research, has been carried out and has great importance in determining the character of human microbiota. The studies on microbiota of farm animal and pets are unprecedented yet. Microbiota has a crucial role in increasing the milk yield in order to increase the yield characteristics of farm animals and to maximize the utilization of feed. Pets, especially dogs, have been accompanied by humans since the early ages and share both the habitat and the microbiota with humans. It has been proven that the presence of the pet has a major role in the development of microbiota, both for adults and especially for newborn children, and reduces the incidence of allergic diseases such as asthma, allergic rhinitis, atopic dermatitis. Microbiota studies in veterinary medicine are relatively new and there is still many issues to be investigated.
\end{abstract}

Keywords: Livestock, microbiota, pet, poultry, probiotic

\section{Giriş}

Mikrobiyota; organizmada yaşayan mikroorganizmalar sistemini, milyarlarca mantar, bakteri ve tek hücrelilerden oluşan, hayati öneme sahip, çok hassas bir süper organı anlatmakta olup, canlılarla birlikte yaşayan özel türlerin tamamını ifade etmektedir. Mikrobiyota, konakçı vücudundan 10 kat daha fazla hücreye ve $10^{12}$ kat daha fazla gene sahiptir (Suchodolski 2011).

Mikrobiyom ise mikroorganizmaların toplam sayısını ve bunların genetik materyalini ifade eder ve mikrobiyota teriminden farklıdır. Mikrobiyom konak için birçok olumlu etki sağlar: geçici bakterilere karşı savunmacı bir bariyer görevi görür; besin yıkımına ve diyetten enerji kazanımına yardımcı olur; enterositler için besin metabolitleri sağlar ve konakçı bağışıklık sisteminin düzenlenmesinde önemli bir rol oynar (Ackerman 2007). Sağlıklı ve stabil bir mikrobiyom aynı anda pro ve anti inflamatuvar etki yaparken, enfeksiyonlara verilen yanıtta aşırı yangıyı önleyerek bir denge sağlamaktadır (Pilla ve Suchodolski 2020).

*ilk yazarın 2017 tarihli doktora seminerinden özetlenmiştir.

Yazışma adresi / Correspondence: DilekEmre Küllük, Ondokuz Mayıs Üniversitesi Veteriner Fakültesi, iç Hastalıkları Anabilim Dalı, Samsun, Türkiye E-posta: emre.kulluk@omu.edu.tr

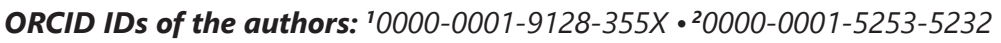


Bağırsak mikrobiyomunun bileşimindeki olumsuz değişimlere disbiyozis denir. İnsanlarda disbiyozisin ülseratif kolit ve Crohn hastalığı gibi yangısal bağırsak hastalıklarına yatkınlık sağladığı ortaya konulmuştur (Tomasello ve ark. 2016). Hayvanlardaki akut veya kronik bağırsak yangıları gibi gastrointestinal sistem disfonksiyonlarının en belirgin nedeni bağırsak disbiyozisidir. Disbiyozis'de mikrobiyotanın yanı sıra kısa zincirli yağ asitleri ve triptofan gibi bakteriyel metabolitlerde de fonksiyon bozuklukları görülmektedir (Pilla ve Suchodolski 2020). Yakın zamanda geliştirilen ve "Disbiyoz İndeksi" olarak adlandırılan PCR tabanlı bir algoritma, veteriner hekimlerin bağırsak disbiyozunu ölçmelerine olanak tanıyan bir araçtır ve hastalığın ilerlemesini ve tedaviye yanıtı izlemek için kullanılabilmektedir (AlShawaqfeh ve ark. 2017). Yapılan son çalışmalar hayvanlarda ve insanlarda obezite Kieler ve ark.(2017), metabolik hastalıklar Montoya-Alonsu ve ark.(2017), kanser Zitwogel ve ark.(2017), nörolojik sistem bozuklukları Wu ve ark.(2016) ve diğer hastalıklar ile disbiyozisin ilişkili olduğunu ortaya koymuştur.

Bağırsak mikrobiyotası, enterik sinir sisteminin gelişimi için gereklidir. Bir nörotransmitter olan ve bağırsak-beyin ekseni teriminin ortaya çıkmasını sağlayan serotoninin yüzde $90^{\prime}$ ı bağırsak duvarından salgılanmaktadır ve burada enterik sinir sisteminden motilite, sekresyon ve kan akışını düzenlemektedir (De Vadder ve ark. 2018). Serotonin üretimi ayrıca kısmen mikrobiyom tarafından, serotoninin bakteriler tarafından doğrudan üretimi veya serotonin öncüsü olan triptofan amino asidinin tüketimi ile kontrol edilmektedir (O' Mahony ve ark. 2015). Ayrıca bağırsak ve bağırsak bakterileri bazı nörokimyasallar üreterek beynin ruh, hafıza ve öğrenme durumunu etkiler. Buna bağlı olarak, disbiyozisin stres, kaygı, anksiyete, depresyon gibi durumları tetikleyebildiği ve şizofreni gibi mental bozuklukların altyapısını oluşturma kapasitesine sahip olduğu bilinmektedir (Dickerson ve ark. 2017; Pilla ve Suchodolski 2020).

Bağırsak mikrobiyotasının bileşimi ayrıca bağışıklık fonksiyonu üzerinde önemli etkilere sahiptir ve yerel antikor üretimini düzenler (Tizard ve Jones 2018). Bağırsakta yardımcı T (T helper) hücre prekürsörleri, mikrobiyotadan alınan sinyale bağlı olarak Treg veya Th17 hücrelerine farklılaşabilmektedir. Homeostazda Treg hücrelerinin üretimi tercih edilir, Treg hücreleri Th17 hücrelerinin üretimi baskılar ve bağırsak duvarında yangının minimal düzeyde meydana gelmesini sağlar. Treg hücrelerinin yokluğunda ise, efektör T hücreleri kontrolsüz olarak mikrobiyal antijenlere yanıt vererek yangıyı tetiklemektedir (Tizard ve Jones 2018). Bazı spesifik bakteri grupları bu süreci etkileyebilir: Örneğin, Clostridium IV ve XIVa grubu üyelerinin Treg indüksiyonunu uyardığı, anti yangısal yanıtı indüklediği, segmentli filamentöz bakterilerin ise yangı öncüsü sinyaller üreten Th17 hücrelerini indüklediği görülmüştür (Ivanov ve ark. 2009; Atarashi ve ark. 2011).

Sırtlan popülasyonlarında, aynı aile grubundaki üyelerinin anal bezlerinde diğer aile üyelerine kıyasla daha fazla benzer mikrobiyal topluluk barındırdığı ve anal bezlerindeki bu mikrobiyal topluluklardan gelen koku sekresyonlarının, aile üyelerinin, grubundaki diğer üyelerini tanımasına olanak sağlayan faktörler olduğu ortaya konmuştur (Theis ve ark. 2012). Patlayıcı tespit köpeklerinde metronidazolun oral yoldan verilmesinin, köpeklerin tespit yeteneğini değiştirdiğini bildirilmiştir. (Jenkins ve ark. 2016).

Yapılan çalışmalar, farelerde diyet değiştirerek veya antimikrobiyallerin uygulanmasıyla bağırsak mikrobiyotasının manipüle edilmesinin beyindeki zihinsel durumda, davranış ve gen ekspresyon düzeylerinde değişikliklere neden olabileceğini göstermektedir ve germ-free farelerde yapılan çalışmalar, mikrobiyotanın olfaktörik epitelin fizyolojisini de değiştirebildiğini ve normal bağırsak mikrobiyotası ile kolonize olan germ-free farelerde kolonizasyondan sonra motor aktivitesinde artış ve anksiyete tepkilerinde azalma görülmüştür. (Diaz ve ark. 2011; Dickerson ve ark 2017). Ayrıca germ free farelerde normal farelere göre ince bağırsak yüzey alanlarının azaldığı, bağırsak vilus ve kriptlerinin kısaldığı, lamina propria katmanının inceldiği, geçiş zamanının uzadığı, yağ asidi konsantrasyonunun ve bağırsak ozmolaritesinin azaldığı ortaya konulmuştur (Al-Asmakh ve Zadjali 2015). Bu bulgular mikrobiyotanın konağın fizyolojisini ve davranışını etkileyebileceğini göstermektedir.

\section{Çiftlik Hayvanlarında Mikrobiyota}

Geviş getiren hayvanlar rumenlerinde, çoğunlukla bakteri, arkea, siliyer protozoa, mantar ve virüslerden oluşan çok çeşitli simbiyotik bir mikrobiyota bulundurmak üzere evrimleşmişlerdir (Firkins ve $\mathrm{Yu}$ 2015). Sığırlar rumen ve bağırsaklarında bitkilerden sağlanan liflerin parçalanmasını sağlayan, protein yapısında olmayan azotu proteine çeviren, çeşitli vitaminleri sentezleyen ve sindirim sistemindeki zararIı bileşikleri temizlemeye yardımcı olan ve bu sayede yemden yararlanmayı ve verimi artıran çok güçlü ve kompleks bir mikrobiyotaya sahiptirler. Bu sindirim sistemi mikrobiyotası hayati bir öneme sahiptir ve rumen ve bağırsak mikrobiyotasının disbiyozisi; sağlık durumu, metan salınımı, süt ve et gibi verim 
özellikleri ve hayvan refahını doğrudan etkilemektedir (Li ve Guan 2017; Difford ve ark. 2018). Sindirim sistemi yollarında bulunan bakteri türlerinin sayısının 5,000'den fazla olduğu tahmin edilmekle birlikte, diyet, beslenme stratejisi ve coğrafi konuma bağlı olarak değişmektedir. Sığırlarda ön mide ve bağırsaklar; içeriğin fermantasyonunu sağlayan bakteriler, arkealar, mantarlar, protozoonlar ve virüslerden oluşan çeşitlilik gösteren kalabalık bir mikrobiyotayı barındırmaktadır ve bakteriyel konsantrasyonları, içeriğin mililitre'sinde $(\mathrm{ml}) 10^{12}-10^{14}$ hücreye ulaşmaktadır (Russel ve Rychlik 2001; Krause ve ark. 2013; Henderson ve ark. 2015).

Sığırlardaki rumen ve bağırsak mikrobiyotasının disbiyozunun; subakut ve akut rumen asidozu, süt yağında azalma, timpani gibi birçok metabolik hastalığın yanı sıra, vajinal kanal ve meme dokusu gibi vücuttaki diğer bölgelerin mikrobiyotalarını da etkileyerek mastitis gibi hastalıkların da ortaya çıkmasına veya şiddetlenmesine sebep olabilmektedir (Khafipour ve ark. 2009; Azad ve ark. 2015; Derakhshani ve ark. 2016; Plaizer ve ark. 2017).

Yapılan çalışmalarda rumen mikrobiyotasının tür ve ırk bazında farklılık gösterebileceği ortaya konulmuştur. Örneğin, aynı diyetle beslenen Holstein ve Jersey ırkı süt sığırları arasında rumen mikrobiyotasının bileşiminde farklııklar tespit edilmiştir ( $\mathrm{Paz}$ ve ark. 2016). Ayrıca, bu çalışmada laktasyon döngüleri ve yaş gibi birçok faktör karşılaştırılmıştır ve bu faktörlerin rumen mikrobiyotasındaki farklılaşmaya katkıda bulunduğu bildirilmiştir (Jami ve ark. 2013; Jewell ve ark. 2015).

Tablo 1. Sığır sindirim sisteminin mikrobiyal karakteri

\begin{tabular}{ll}
\hline Rumen & Kalın Bağırsaklar \\
\hline Bacteroidetes & Buzağılarda; \\
Firmicutes & Bacteroidetes \\
Fibrobacter & Firmicutes \\
Arkeler & Atopobium \\
Protozoa türleri & Bifidobacteria \\
& \\
& Sığırlarda; \\
& Bacteroidetes \\
& Firmicutes \\
& Fibrobacter \\
\hline
\end{tabular}

Son yıllarda, süt ineklerinin süt üretim potansiyeli tüm dünyada önemli ölçüde artmıştır ve buna bağlı olarak süt ineklerinin ihtiyaçlarının karşılanması ve süt verimlerinin artıııması için rasyonlarında değişiklikler yapılarak yüksek enerjili diyetlere geçilmiştir. Bu diyetler, mikrobiyotanın kompozisyonunu ve işlevselliğini değiştirerek ve fırsatçı patojenlerin kolonizasyonuna yol açarak sindirim sistemini mik- robiyotasını olumsuz etkileyebilmektedirler (Russel ve Rychlik 2001; Plaizer ve ark. 2008; Krause ve ark. 2013).

\section{Kanatlı Mikrobiyotası}

Bütün omurgalılar gibi, kanatılılar da bağırsaklarında çeşitli konakçılara beslenme ve patojenlerden koruma sağlamada önemli görevlere sahip çeşitli mikroorganizma topluluklarını barındırır. Kanatlı mikrobiyotası alanında, araştırmalar daha çok tavuk gibi yetiştirme önemi olan kanatlı türleri üzerinde yoğunlaşmıştır. (Waite ve Taylor 2015). Tavukların gastrointestinal sistemi, bakterilerin yoğunlukta olduğu karmaşık mikrobiyal topluluklarla (bakteriler, mantarlar, arkeler, protozoalar ve virüsler) yoğun bir şekilde kuşatılmıştır (Wei ve ark. 2013). Tavuk gastrointestinal sistemi, diyet ve sağlık arasındaki bağlantıyı sağlayan karmaşık ve biyoçeşitlilik açısından zengin bir mikrobiyal topluluğa ev sahipliği yapmaktadır. Tavuklarda sindirim sistemi mikrobiyotası yaklaşık olarak 500 filotipe ve 1 milyon bakteriyel gene ev sahipliği yapar ve bu da tavuk genomundaki sayının yaklaşık 40-50 katına eşittir (Maki ve ark. 2019). Bu bakteriler vitaminler ( $K$ vitamini ve $B$ vitamini grupları), kısa zincirli yağ asitleri (asetik asit, bütirik asit ve propiyonik asit), organik asitler (laktik asit) ve antimikrobiyal bileşikler (bakteriyosinler) üretmekte ve hayvan için beslenme ve korunma sağlayan non-patojenik bağışıklık yanıtını uyarmaktadır (Jeurissen ve ark. 2002; Apajalahti 2005; Dibner ve Richards 2005; Yegani ve Korver 2008). Son yıllarda yapılan çalışmalar ise bağırsak mikrobiyotasının genç broilerlerin immünolojik fonksiyonlarını modüle edebileceğini ve ayrıca mikrobiyotanın metabolik ve immun fonksiyonu geliştirmenin yanı sıra yangısal yanıta töleransı artırdığını da göstermektedir (Rodrigues ve ark. 2020).

Kanatlı gastrointestinal sistemi kursak, proventrikül, taşıık, duodenum, jejenum, ileum, sekum, kalın bağırsak ve kloakadan oluşur (Yeoman ve ark. 2012).

Kursak yaklaşık olarak $10^{8}-10^{9}$ koloni oluşuran birim/ gram (kob/gr) bakteriye ev sahipliği yapmaktadır ve kursaktaki baskın tür Lactobacillus türleri 'dir (Gong ve ark. 2007). Taşlıktaki mikrobiyota kursaktakine benzer fakat $\mathrm{pH}$ daha düşük olduğundan dolayı bakteriyel aktivite daha düşüktür. Taşlıktaki bakterileri türleri Lactobacilli, Enterococci, Enterobacteria türleridir (Rehman ve ark. 2007). İnce bağırsak segmentleri arasında en düşük bakteriyel yoğunluk kısa geçiş süresi ve salgılanan safra sıvısından kaynaklı olarak duodenumda bulunur ve genellikle Clostridia, Streptococci, Enterobacteria ve Lactobacilli türlerinden oluşmaktadır (Waite ve Taylor 2015). 
Illeum'da baskın tür Lactobacillus olmakla birlikte bunu Clostridiaceae, Streptococcus Enterococcus aileleri izlemektedir. Sekumda ise baskın olarak Firmicutes ve Bacteroidetes filumları tespit edilmiştir (Kumar ve ark. 2018).

\section{Su Canlılarında Mikrobiyota}

Genetik, beslenme ve çevresel faktörlerden etkilenebilen deniz ve tatlı su türlerinin endojen mikrobiyotasında bulunan taksonlarda çok çeşitli varyasyonlar bulunmaktadır. Aeromonas, Alcaligenes, Alteromonas, Carnobacterium, Flavobacterium, Micrococcus, Moraxella, Photobacterium, Pseudomonas ve Vibrio türleri çeşitli deniz türlerinin baskın mikrobiyotalarını oluştururken (Balcázar ve ark 2010; Dhanasiri ve ark. 2011; Askarian ve ark. 2012); tatlı su türlerinde ise Enterobacteriaceae ailesinden Acinetobacter, Aeromonas, Flavobacterium, Lactococcus ve Pseudomonas, ve ayrıca zorunlu anaerobik bakteri türlerinden Bacteroides, Clostridium ve Fusobacterium baskın olarak bulunmaktadır (Li ve ark. 2012; Wu ve ark. 2012).

\section{Pet Mikrobiyota Çalışmaları}

Kedi ve köpeklerde üzerinde en çok çalışılan başlıca mikrobiyota alanlarl; gastrointestinal sistem, solunum sistemi ve deri sistemi mikrobiyotasıdır (Suchodolski 2011).

İnsanlar ve çiftlik hayvanlarıyla karşılaştırıldığında, kedi ve köpekler nispeten daha basit bir gastrointestinal sisteme sahiptirler. Gastrointestinal sistem, insan ve diğer hayvan türlerinde başlıca mikrobiyota yaşam alanıdır. Memeli sindirim sistemi mikrobiyotası çeşitli ve karmaşık, birbirlerine bağımlı ve rekabet etmeyen çok sayıda türden oluşmuştur (Eckburg ve ark. 2005; Ley ve ark. 2008).

Mikrobiyota kompozisyonu gastrointestinal sistem boyunca farklılıklar gösterir. Distal bölümlerde anaerobik bakteri grupları ağırlıkta iken, proksimal bölümlerinde ise aerobik ve anaerobik bakterilerin daha eşit dağıldığı gözlemlenmiştir (Simpson ve ark. 2002; Suchodolski ve ark. 2008).

Sindirim sistemi mikrobiyotası birçok mekanizma aracılığıyla konakçıya fayda sağlar. Kommensal bakteriler geçici patojenlere karşı savunma bariyeri oluşturur. Besin sindirimine yardımcı olurlar, konakçı için önemli metabolitleri sağlarlar ve ayrıca konakçının bağışıklık sistemini modüle etmede önemli bir işlevleri vardır (Suchodolski 2011).

Midedeki ana bakteri türleri Helicobacter ve Lactobasillus spp.dır. Köpeklerin mide biyopsisinden bakteriyel kültür teknikleri kullanılarak yapılan bir çalışmada midedeki bakteri sayısı $10^{6} \mathrm{kob} / \mathrm{g}$ olarak bulunmuş ve bulunan dizinlerin en fazla Proteobacteria filumuna $(\% 99,6)$ ait olduğu saptanmıştır. Ayrıca Firmicutes filumuna ait az sayıda $(\% 0,3)$ dizin bulunmuştur. Proteobacteria filumundan ise en çok Helicobacter spp. türlerine rastlanmıştır $(\% 98,6)$ (Benno ve Nakao 1992; Garcia-Mazcorro ve ark. 2012).

Tablo 2. Kedi ve Köpeklerde Lokalizyona Göre Baskın Bakteri Grupları

\begin{tabular}{|c|c|c|}
\hline & KÖРЕК & KEDi \\
\hline MIDE & $\begin{array}{l}\text { Helicobacter } \\
\text { Lactobasillus spp. } \\
\text { Proteobacteria }\end{array}$ & $\begin{array}{l}\text { Helicobacter } \\
\text { Lactobasillus spp } \\
\text { Proteobacteria }\end{array}$ \\
\hline DUEDENUM & $\begin{array}{l}\text { Firmicutes, } \\
\text { Proteobacteria, } \\
\text { Bacteroidetes, } \\
\text { Spirochaetes, } \\
\text { Fusobacteria } \\
\text { Actinobacteria }\end{array}$ & $\begin{array}{l}\text { Bacteriodies } \\
\text { Firmicotes } \\
\text { Fusobacteria }\end{array}$ \\
\hline JEJENUM & $\begin{array}{l}\text { Proteobacteria } \\
\text { Firmicutes } \\
\text { Actinobacteria } \\
\text { Spirochaetes } \\
\text { Bacteroidetes } \\
\text { Fusobacteria } \\
\end{array}$ & $\begin{array}{l}\text { Enterococcus } \\
\text { Streptococcus spp } \\
\text { Lactobacillus spp. }\end{array}$ \\
\hline İLEUM & $\begin{array}{l}\text { Proteobacteria } \\
\text { Firmicutes } \\
\text { Actinobacteria } \\
\text { Spirochaetes } \\
\text { Bacteroidetes } \\
\text { Fusobacteria } \\
\end{array}$ & $\begin{array}{l}\text { Clostridium } \\
\text { Bacteriodes spp. }\end{array}$ \\
\hline KOLON & $\begin{array}{l}\text { Fusobacteria } \\
\text { Bacteroides Firmicutes }\end{array}$ & $\begin{array}{l}\text { Streptococcus spp } \\
\text { Lactobacillus spp. } \\
\text { Erysipelotrix spp. } \\
\text { Clostridium } \\
\text { Bacteriodetes } \\
\text { Proteobacteria } \\
\text { Actinobacteri }\end{array}$ \\
\hline
\end{tabular}

Duodenal mikrobiyota 6 filum içermektedir. Bunlar; Firmicutes $(\% 46,4)$, Proteobacteria $(\% 26,6)$, Bacteroidetes (\%11,2), Spirochaetes (\%10,3), Fusobacteria $(\% 3,6)$ ve Actinobacteria (\%1) (Xenoulis 2008).

Jejenumda ise 10 farklı bakteri filumu tespit edilmiştir. Başlıca bakteri filumları Proteobacteria $(\% 46,7)$, Firmicutes $(\% 15,0)$, Actinobacteria $(\% 11,2)$, Spirochaetes $(\% 14,2)$, Bacteroidetes $(\% 6,2)$ ve Fusobacteria'dır $(\% 5,4)$. En yaygın bakteri türleri ise Gamma-proteobacteria ( \%40), Spirochaetes ( \%13), Actinobacteria ( \%12), Clostridia ( \%10), Bacteroidetes ( \%6), Fusobacteria ( \%4), ve Alpha-proteobacteria ( \%3) dır (Suchodolski ve ark. 2009).

Kalın bağırsaklar en fazla bakteri yoğunluğuna ve çeşitliliğine sahip olan bölgedir $\left(10^{9}-10^{11} \mathrm{kob} / \mathrm{g}\right)$. Sağlıklı köpeklerde kolon mikrobiyotasında baskın 
olarak Fusobacteria, Bacteroides ve Firmicutes (Her biri \%30 oranında) içermektedir (Suchodolski ve ark. 2008).

Sindirim sistemi mikrobiyotası sadece bakterileri değil, aynı zamanda mantarları, arkeleri ve virüsleri de içerir. Bağırsak bölgesinden PCR (Polimer Zincir Reaksiyonu) analizi yapılan bir çalışmada sağlıklı köpeklerin \%61'inde, kronik enteropatili köpeklerin ise \%79'unda mantar DNA'sı tespit edilmiştir ve en çok identifiye edilen mantar sınıfı Saccharomycetes'tir (Suchodolski ve ark. 2008).

Kedi ve köpeklerde bildirilmiş viral filotipler Rotavirus, Coronavirus, Parvovirus, Norovirus, Astrovirus, Distemper virus, ve Paramyxoviruslar'dır (Mochizuki ve ark. 2001; Kempf ve ark. 2010).

Solunum sistemi mikrobiyotasına ilişkin araştırmaların çoğu insanlarda yapılmıştır ve insanlarla birlikte çevreyi paylaşan evcil hayvanlardaki hava yolu mikrobiyotasının bileşimi hakkında bilgiler daha sınırlıdır. Yangısal hava yolu hastalıkları, köpeklerde ve kedilerde kronik bronşitte ve kedilerde alerjik astımda yaygındır. İnsanlarda, sağlıklı ve astımlı solunum yolları arasındaki mikrobiyal bileşimdeki farklılıklar bildirilmiştir (Hilty ve ark. 2010; Marri ve ark. 2013; Huang ve ark. 2015). Son zamanlardaki çalışmalarda köpeklerde solunum yolu mikrobiyotasında Protobacteria, Tenericutes ve Actinobacteria'lar identifiye edilmiştir ve sağlıklı köpeklerde ortaya konan bu veriler, enfeksiyöz ve enfeksiyöz olmayan yangısal solunum hastalıklarında mikrobiyal toplulukların rolünün anlaşılması açısından önemlidir (Ericsson ve ark. 2016). Kedilerde ise sağlıklı solunum yolu mikrobiyota kompozisyonunu belgeleyen bir çalışma ise henüz yayınlanmamıştır (Vientós-Plotts ve ark. 2017).

Köpeklerde yapılan mikrobiyota çalışmalarında atopik dermatitisli hayvanların mikrobiyotasındaki bakteriyel ve fungal toplulukların sağlıklı hayvanlara göre daha az çeşitlilik gösterdiği saptanmıştır. İnsanlarla benzer şekilde, her köpekteki farklı deri bölgeleri çeşitli ve kendine özgü mikrobiyotayla kuşatılmış ve farklı köpekler ve farklı bölgelerde ciddi kişisel farklılıklar belirlenmiş ve ayrıca mukozal yüzeylere nazaran (dudaklar, burun, kulak ve konjonktiva) kıllı bölgelerde daha yüksek mikrobiyal bir çeşitlilik tespit edilmiştir. Burun deliği ve konjuctiva en düşük mikrobiyal yoğunluğu içerirken, aksillar bölge ve burnun dorsal kısmı en yüksek mikrobiyal çeşitliliği göstermiştir. Ortalama olarak, köpek burnu dorsalinde yaklaşık 300 farklı bakteri cinsi tespit edilmiştir. Bütün bu yüzeylerdeki baskın filumlar, Proteobacteria, Firmicutes, Actinobacteria ve Bacteroidetes'dir (Rodrigues-Hoffmann ve ark. 2014). Kedilerde ise deri mikrobiyotasına Micrococcus, Acinetobacter, Streptococci ve Staphylococci'nin egemen olduğu bulunmuştur (Krogh ve Kristensen 1976).

\section{Hayvan ve İnsan Mikrobiyota Etkileşimi}

Evcil hayvanların insan sağlığına yarar sağladığı fikri, ilk olarak 1989 'da alerjik hastalık riskini aşırı hijyenik ortamlara bağlayan David Strachan tarafından ortaya atılmıştır (Strachan 1989). Bebeklik evresinde bağırsak mikrobiyal disbiyozun alerjik hastalığın gelişimi ile ilişkili olduğuna dair daha fazla kanıt ile bu görüş mikrobiyota hipotezi olarak revize edilmiştir (Wold 1998; Hesselmar ve ark. 1999; Litonjua ve ark. 2002; Ownby ve ark. 2002; Lodge ve ark. 2012; Nermes ve ark. 2013; Ezell ve ark. 2013).

Birlikte yaşayan insan ve hayvanların mikrobiyotalarında en çok benzerliğin olduğu bölge deri ve tüy bölgesidir. Mikrobiyal açıdan yetişkinlerin cilt mikrobiyotası, diğer köpeklere kıyasla kendi köpeği veya köpeklerinin mikrobiyotası ile daha benzerdir Köpekleri olan insanlar birbirleri ile, köpekleri olmayan insanlardan daha fazla ortak bakteri filotipini paylaşırlar. Köpekleri olan, fakat birlikte yaşamayan iki insan ortalama olarak; köpekleri olmayan fakat birlikte yaşayan insanlardan daha çok ortak filotipe sahiptir (Song ve ark. 2013).

Köpekler ve sahipleri arasında en çok benzerlik gösteren taksonlar; Betaproteobacteria (Methylophilaceae) ailesi, Actinobacteria ailesi ve Acidobacteria ailesidir (Lauber ve ark. 2009).

Ev hayvanlarına prenatal maruziyeti değerlendiren altı çalışmanın bir meta-analizinde, özellikle prenatal köpek sahipliğinde, bebeklerde alerjik hastalık (atopik dermatit, astım) riskinin azaldığı bildirilmiş̧ir Ayrıca 24 bebekte yapılan bir pilot çalışmada ise, evcil hayvan varlığında 3 aylık bebeklerde bağırsaklarındaki mikrobiyal zenginliğinin ve çeşitliliğin daha fazla olduğu ve mikrobiyotalarının daha fazla hayvan spesifik Bifidobacterium pseudolongum içerdiği ortaya konmuştur ve bu hayvan-insan mikrobiyota geçişinin önemli bir göstergesi olarak kabul edilmiştir (Lodge ve ark. 2012; Azad ve ark. 2013; Nermes ve ark. 2013).

Ayrıca köpeklerin evcilleşip insanlarla birlikte yaşamasını değerlendirmek amacıyla vahşi kurtlarla evcil köpeklerin bağırsak mikrobiyotalarının karşılaştııılığı bir çalışmada kurtlarda bulunan Alistipies, Pseudomonas, Slackia, Subdoligranulum, Eubacterium coprostanoligenes grubu ve Barnesiella 'nın köpek mikrobiyotasında bulunmadığı ve bunun da vahşi atalarından farklı olarak yaşam tarzının ve in- 
san etkisinin mikrobiyota üzerinde etkili olduğunu göstermektedir. Buna paralel olarak aynı çalışmada vahşi kurtlarda bulunmayan Indeed, Dorea, Parabacteroides, Streptococcus, Bacteriodales ve Clostridiales ailelerinin insan ve evcil köpeklerde bulunduğu ortaya konulmuştur. (Alessandri ve ark. 2019)

\section{Antibiyotik Kullanımı}

Mikrobiyota üzerine etki eden en önemli faktörlerden birisi antibiyotik kullanımıdır. Antibiyotikler sadece hedef patojene spesifik toksisiteye sahip olmayıp, mikrobiyotaya da etkileri vardır. Yapılan bir çalışmada 7 gün boyunca klindamisin uygulama sonrasında mikrobiyotadaki Bacteroides cinsinin 2 yıl sonra bile tam olarak normal kompozisyonuna dönemediği saptanmıştır (Jernberg ve ark. 2007).

Antibiyotik kullanımının üzerlerinde etkilerinin fazla olduğu gözlenen ana bakteri grupları arasında başlıca Actinobacteria, Bacteroidetes, Firmicutes ve Proteobacteria grupları bulunmaktadır. Bu ana gruplardaki bazı cinsler Bifidobacterium, Bacteroides, Faecalibacterium, ve Escherichia göreceli olarak daha fazla etkilerin gözlendiği cinslerdir. Diğer etkilenen bakteri grupları arasında Fusobacteria (Fusobacterium), Planctomycetes (Gemmata) ve Verrucomicrobia (Akkermansia) gibi bakteri grupları bulunmaktadır (Ladirat ve ark. 2013; Panda ve ark. 2014; Ferrer ve ark. 2017).

Mikrobiyota üzerindeki en fazla etki gösteren antibiyotiklerin başında sık kullanımları nedeniyle beta-laktam ve florokinolon grubu antibiyotikler gelmektedir. Öte yandan kombine tedavi uygulamalarına da çok sık başvurulduğu için, mikrobiyom üzerinde de kombine etkiler sıklıkla oluşmaktadır (Panda ve ark. 2014).

Texas Üniversitesi Kanin Mikrobiyota Disbiyozis Indeksinin verilerine göre pek çok köpekte antibiyotik kullanımı sonrası birkaç hafta içerisinde, bağırsak mikrobiyotası eski kompozisyonuna dönmekle birlikte, bazı hayvanlarda ise bu süreç oldukça uzamaktadır (Suchodolski ve ark. 2016).

\section{Mikrobiyota-Diyet İlişkisi}

Besin bileşiminin ve yem içeriğinin, gastrointestinal fonksiyonunu, mikrobiyota bileşimini ve hayvan bağırsağındaki bakteriyel metabolik ürünlerini önemli ölçüde etkilediği bilinmektedir (Grześkowiak ve ark. 2015).

Farklı türlerde yapılan çeşitli çalışmalar, diyet kompozisyonunun- özellikle etobur ve otçul diyetlerinde bulunanlar gibi büyük makro besin farklılıklarının farklı bağırsak mikrobiyom profilleri üzerinde etkileri olduğunu göstermiştir (Pilla ve Suchodolski 2020).

Zorunlu etobur olarak sınıflandırılmalarına rağmen, günümüzde evcil kedi ve köpekler omnivordur ve ticari mamalarda bulunan çok çeşitli diyet karbonhidratlarını metabolize edebilmektediler (Swanson ve ark. 2011; Rochus ve ark. 2014).

Son yıllarda köpekler için, Kemik ve Çiğ Gıda (Bone and Raw Food = BARF) diyeti olarak adlandırılan yeni bir beslenme türü oldukça popüler hale gelmiştir. BARF diyeti, pişmemiş et, kemikler ve nispeten daha düşük seviyelerde sebze, yumurta ve süt ürünlerini içerir (van Bree ve ark. 2018).

Ticari mamalar ile Kemik ve Çiğ Gıda (BARF) diyetini karşılaştıran bir çalışmada BARF diyeti ile beslenen köpeklerde Peptostreptococcus ve Faecalibacterium cinslerini içeren Firmicutes filumunda ve ayrıca Bacteroides ve Prevotella cinslerini içeren $\mathrm{Ba}$ cteriodetes filumunda azalma görülmüştür (Schmidt ve ark 2018).

Kedilerde yapılan benzer bir çalışmada da diyetin mikrobiyota kompozisyonunu ve mikrobiyal metabolitlerin seviyesini etkilediği tespit edilmiştir (Wernimont ve ark. 2019).

Pet hayvanlarında olduğu gibi çiftlik hayvanlarında da diyetin mikrobiyota üzerine etkileri vardır. Sığırlarda diyetin mikrobiyota üzerine etkilerini değerlendirmek üzere yapılan bir çalışmada mera besisi ve toplam karışım rasyon ile beslenen sığırların rumen mikrobiyotasını incelenmiş ve rumen mikrobiyotasındaki bakteri ve arkeler üzerinde önemli farklılıklar bulunduğu ve ayrıca rumen protozoalarının diyet farklılıklarından mikrobiyotadaki bakterilerden çok daha az etkilendiği belirlenmiştir. Aile düzeyinde, toplam karışım rasyon ile beslenen hayvanlarda Fibrobacteraceae'nin ve mera besisi ile beslenen hayvanlarda ise propiyonat üreten Veillonelaceae yüksek bulunmuş ve mikrobiyotanın diyetle ilişkili olduğu ortaya konulmuştur. (De Menezes ve ark. 2011).

\section{Probiyotik Kullanımı}

Probiyotikler "yeterli miktarda alındıklarında endojen mikrofloranın özelliklerini geliştirerek, konakçı sağlığını olumlu yönde etkileyen canlı mikroorganizmalar" olarak tanımlanmaktadır. Bir ürünün probiyotik olarak tanımlanabilmesi için, mide asiditesi ve safra asitlerine karşı dirençli olması, sindirim kanalında canlı kalabilmesi, bağırsak epiteline tutunabilmesi, mikrobiyotaya adapte olması, sindirim sisteminde kolonize olabilmesi, antimikrobiyal maddeler salgılayabilmesi (bakteriyosin gibi), patojen ve 
toksik olmaması, konakçı sağlığı üzerinde olumlu etkileri olması ve üretim ve depolama sırasında stabil olması, canlı kalabilmesi gerekmektedir (FAO/WHO, 2002).

Probiyotiklerin konakçı üzerinde; yağ asitleri, laktik asit ve asetik asit gibi antibakteriyel bileşiklerin üretimi, potansiyel patojenler ile besin ve bağlanma bölgeleri için rekabet etme, mikrobiyal metabolizmanın değiştirilmesi, bağışıklığın uyarılması gibi etki şekilleri vardır (Sarowska ve ark. 2013).

Probiyotikler sitokin sentezini ve intestinal mikroflorayı düzenler. Enterositlerdeki Toll-like reseptörleri (TLR) ve proteoglikan tanıyıcı proteinlere etkilidir ve Th1 aktivasyonuna yol açarlar. Th1 sitokinleri artar ve Th2 sitokinleri azalır; böylece mukozal IgA sekresyonu, alerjen spesifik B ve T hücre yanıtı düzenlenir (Winkler ve ark. 2007). Probiyotikler, bağırsak mukozasına bağlılıklarına müdahale ederek veya mukus / müsin üretimini indükleyerek potansiyel patojenlerle rekabet edebilmektedirler (Collado ve ark. 2007).

Lactobacillus acidophilus, Lactobacillus bulgaricus, Lactobacillus casei, Lactobacillus plantarum, Lactobacillus rhamnosus gibi başlıca probiyotik türleri epitelyal hücrelere yapışarak patojen kolonizasyonu azaltıp aynı zamanda metabolitlerin üretimi ile patojen ve non-patojen bakteriler arasında bir denge sağlamaktadır. (De Vrese ve ark. 2008).

Tablo 3. Bazı probiyotik bakterilerin yararları.

\begin{tabular}{|c|c|}
\hline Bakteri Adı & Yararları \\
\hline Lactobacilli spp. & $\begin{array}{l}\text { Besinlerin sindirimini ve emilimini artııır, } \\
\text { Patojen bakterilerin kolonizasyonunu önle }\end{array}$ \\
\hline Bifidobacterium spp. & Bağışıklık fonksiyonunu uyarır \\
\hline Enterococcus spp. & Patojen bakterilerin üremesini engeller \\
\hline Bacteroides spp. & Vitamin Sentezi \\
\hline Streptococci spp. & Bağışıklık fonksiyonunu uyarır \\
\hline Fusobacteria spp. & Besinlerin sindirimini ve emilimini artırır \\
\hline Eubacterium spp. & Patojen bakterilerin üremesini engeller \\
\hline $\begin{array}{l}\text { Saccharomyces } \\
\text { boulardii }\end{array}$ & $\begin{array}{l}\text { Bağırsak bariyerini geliştirir, } \\
\text { Yangıyı baskılar }\end{array}$ \\
\hline
\end{tabular}

Evcil hayvanlarda probiyotik kullanımının bazı yararlı etkileri; Bağışıklık sisteminin modülasyonu, stres durumlarına yardımcı olma, enteropatojenlerin neden olduğu enfeksiyonlardan koruma, büyüme ve gelişmede artış, alerjik hastalıkların ve son zamanlarda ise sıkça görülen obezite probleminin kontrolüdür. (Grześkowiak ve ark. 2015).

Veteriner hekimlikte probiyotiklerin canlı üzerine olumlu etkilerini ortaya koymak üzerine yapılmış birçok çalışma bulunmaktadır;

Köpeklerde yapılan çalışmalarda Enterococcus faecium SF68 türü uygulanan köpeklerde plasebo grubuna kıyasla fekal IgA ve distemper virüs aşısına özgü serum IgG ve IgA konsantrasyonunun daha yüksek olduğu ölçülmüştür ve ayrıca uzun süreli uygulamalarda kedilerde ve köpeklerde potansiyel bir immun modülasyon etkisinin görüldüğü ortaya konmuştur ve ayrıca köpeklerde ilk aşılamadan 4 hafta sonra Enterococcus faecium SF68 uygulanan köpeklerde lenfosit proliferasyonu ve kuduz titresinin daha yüksek olduğu tespit edilmiştir (Benyacoub ve ark. 2003). Kedi ve köpeklerde barınağa ilk getirildiğinde E.faecium SF68 $\left(2.1 \times 10^{9} \mathrm{kob} / \mathrm{g}\right)$ uygulanan kedilerde uygulanmayanlara göre enterit ve ishal görülme yüzdesinin daha düşük olduğu, fakat köpeklerde ise bu insidanslarda bir değişme olmadığı saptanmıştır; bu veriler probiyotiklerin etkilerinin hayvan türlerine spesifik olabileceğini göstermektedir. (Bybee ve ark. 2011). Ayrıca probiyotik organizmaların kedi ve köpeklerde serum lipid ve protein seviyelerini kontrol etme potansiyelinin olduğu; probiyotik uygulaması sonucu kanda trigliserid ve albümin konsantrasyonlarında azalma şekillendirdiği, lökositlerin fagositik aktivitesinde artışın yanısıra düşük kolesterollü hayvanlarda kolesterol seviyelerinin fizyolojik seviyelere geldiği gözlemlenmiştir (Marcináková ve ark. 2006; Strompfová ve ark. 2014). Köpeklerde yangısal bağırsak hastalığında insan kaynaklı VSL\#3 (L. plantarum, L. delbrueckii subsp. bulgaricus, L. casei, L. acidophilus, Bifidobacterium breve, B. longum, Bifidobacterium infantis ve Streptococcus salivarus subsp. thermophilus türlerini içeren bir probiyotik) 112-225 $\times 10^{9} \mathrm{kob} / 10 \mathrm{~kg}$ dozunda 60 gün boyunca uygulanmış ve klinik tabloda iyileşmenin yanı sıra CD3 + $T$ hücre infiltrasyonunda azalma ve bağırsak mikrobiyotasında normalleşme görülmüştür (Rossi ve ark. 2014).

Tablo 4. Kedi ve köpeklerde yetkilendirilmiş probiyotikler

\begin{tabular}{llll}
\hline Yetkilendirme Numarası & Katkı Adı & Hayvan Türü & Minimum içerik (Kob/kg) \\
\hline 4b1820 & Bacillus Subtilis DSM 15544 & Köpek & $1 \times 10^{9}$ \\
4b1705 & Enterococcus faecium NCIMB 10415 & Kedi & $7 \times 10^{9}$ \\
\multirow{2}{*}{ 4b1715 } & Köpek & $2.5 \times 10^{9}$ \\
& Lactobacillus Achidophilus CECT 4529 & Kedi & Köpek \\
\hline
\end{tabular}


Kronik böbrek hastalıklı kedi ve köpeklerde artış gösteren proteinlere bağlı üremik toksinlerden indoksil sülfat ve p-creasol'un bağırsak mikrobiyotası ile ilişkili olduğu saptanmıştır (Summers ve ark. 2019). Yapılan çalışmalarda probiyotik kullanımının kronik böbrek yetmezliğinde üremik toksinler ve glomerüler filtrasyon hızı üzerine pozitif etkileri olduğu belirtilmiştir (McCain ve ark. 2011; Lippi ve ark. 2017).

Süt sığırlarında rasyona Lactobasillus spp., Acetobacter fabarum ve Candida ethanolica içeren bir probiyotik eklenerek süt verimi ve yağını değerlendirildiği bir çalışmada probiyotik uygulanan grupta süt veriminin ve yağ oranının artma eğiliminde olduğu ortaya konulmuştur (Olchowy ve ark. 2019). Buzağılarda probiyotiklerin büyüme üzerine etkilerini inceleyen çalışmalarda canlı ağılık artışı (Dar ve ark. 2017), vücut skoru (Windschitl ve ark. 1991) ve kuru madde alımında (Jatkauskas ve Vrotniakiene 2010) artışlar ortaya konulmuştur. Büyüme performansının incelendiği bir çalışmada ise Lactobacillus acidophilus ve prebiyotik uygulanan buzağılarda uygulanmayanlara göre büyüme performansında ciddi olumlu farklar ortaya konulmuştur (Ratre ve ark. 2019). Buzağı ishallerinde 2 ve daha çok gün probiyotik olarak Enterococcus faecium M74 uygulanan buzağılarda buzağı ishali görülme ortalamasının \%50'den \%30'a düştüğü görülmüştür (Jatkauskas ve Vrotniakiene 2010). Ayrıca aşılama ve probiyotik takviyelerinin buzağı ishalleri üzerine etkisi incelendiğinde maternal aşılama ve probiyotik kombinasyonunun tek başına maternal aşılamadan ve probiyotik takviyesinden daha iyi sonuçlar verdiği saptanmıştır (Avila ve ark. 1995).

Broiler civcivlerinde 14 günlük civcivlere deneysel olarak oral yolla Eimeria tenella ookistleri verilerek enfekte edilmiş ve 14 . gün ile 35 . gün arasında içme suyu ile birlikte Pediococcus acidilactici ve Bacillus subtilis içeren probiyotik $\left(1 \times 10^{7} \mathrm{kob} / \mathrm{ml}\right.$ dozunda) uygulanarak; yem tüketimi, canlı ağırlık ve yemden yararlanmanın yanı sıra sekum ve ileumdaki villus yüksekliği ve kript derinliği ölçülerek bir antikoksidiyal olan salinomisin ile etkinliği karşılaştırılmıştır. Probiyotik uygulanan civcivlerin villus yükseklikleri, kript derinliği ve ayrıca canlı ağırlık artışı antikoksidiyal grubuna göre daha olumlu bulunmuştur (Erdoğmuş ve ark. 2019). Broiler tavuklarında ise Lactobacillus spp. türlerinin C.jejuni'yi in vitro olarak öldürmek için yeterli miktarda laktik asit üretebildiğini ve üretilen laktik asitin C. jejuni'nin membran bütünlüğünü bozarak etki ettiği ortaya konulmuştur (Neal-McKinney ve ark. 2012).

\section{Sonuç}

Mikrobiyota konusu özellikle 2000'li yılların başından beri dikkat çekmeye başlamış ve keşfedilen şaşırtıcı fonksiyonları sonucu, kısa sürede kalın bağırsak "ikinci beyin" olarak adlandırılmıştır. Veteriner sahada ise mikrobiyotanın karmaşık yapısı, fonksiyonları ve organizma üzerine etkileri yeni yeni araştırılmaya ve üstüne düşünülmeye başlanmıştır.

İmmun fonksiyonlardan, endokrin sisteme, davranış fizyolojisinden gelişim ve rejenerasyona çok geniş bir etki skalası olan mikrobiyota kompozisyonu; veteriner hekimlikte de insan-hayvan etkileşimi, verim özellikleri ve sürü sağlığına etkisi, ekonomik ve toplumsal yönlerden hızla araştırılması gereken bir sahadır.

Yapılan araştırmalar, hastalıklarda doğru mikrobiyota manipülasyonlarının tedaviye katkı sağladığını ortaya koymuştur ve görünen o ki prebiyotik ve probiyotiklerin (sinbiyotik kombinasyon) potansiyel terapötik etkinliği günden güne aydınlanacaktır.

Diğer yandan, veteriner klinik pratikte çok yoğun karşılaşılan rastgele probiyotik reçete etme alışkanlığının ne derece fayda sağladığı oldukça tartışmalıdır. Pet klinik hekimliği ele alındığında, ne yazık ki henüz kedi ve köpek barsağından izole edilmiş ticari bir probiyotik müstahzarı bulunmamaktadır. $\mathrm{Bu}$ durumda insan probiyotikleri kullanımında, kedi ve köpek gastrointestinal asidite, kompozisyon ve arzu edilen koloni seçimi büyük önem taşımaktadır. Bir örnek vermek gerekirse, Bifidobacterium ailesine ait koloniler, kedi ve köpek midesindeki pH'a bağlı olarak, daha bağırsağa inemeden inaktive olmaktadır.

Güncel tıp, bilimsel çalışmaları, sağığın anahtarının koruyucu hekimlik olduğu gerçeği bazında şekillendirmektedir. Mikrobiyota konusunda mevcut çalışmalar, veteriner hekimlikte de mikrobiyota araştırmalarının sağlık ve ekonomik sahada önemli karşılığı olduğunu işaret etmektedir. Bu nedenle veteriner sahada gelecek perspektifinde kırılma noktası olabilme potansiyelini taşıyan mikrobiyota fenomenine, en kısa sürede daha fazla odaklanılması gerekmektedir.

\section{Kaynaklar}

Ackerman N (2007). The canine microbiome. Vet. Nurs. J. 8(1). doi: 10.12968/vetn.2017.8.1.12

Al-Asmakh M, Zadjali F. (2015) Use of Germ-Free Animal Models in Microbiota-Related Research. J Microbiol Biotechnol. 25 1583-1588. doi: 10.4014/jmb.1501.01039

Alessandri G, Milani C, Mancabelli L, Mangifesta M, Lugli GA, Viappiani A, Duranti S, Turroni F, Ossiprandi MC, van Sinderen D, Ventura M. (2019) Metagenomic dissection of the cani- 
ne gut microbiota: insights into taxonomic, metabolic and nutritional features. Environ Microbiol. 21, 1331-1343. doi: 10.1111/1462-2920.14540

AlShawaqfeh MK, Wajid B, Minamoto Y, Markel M, Lidbury JA, Steiner JM, Serpedin E, Suchodolski JS. (2017) A dysbiosis index to assess microbial changes in fecal samples of dogs with chronic inflammatory enteropathy. FEMS Microbiol Ecol. 1, 93. doi: 10.1093/femsec/fix136

Apajalahti J. (2005) Comparative gut microflora, metabolic challenges, and potential opportunities. J Appl Poult Res. 14, 444453. doi: 10.1093/japr/ 14.2.444

Askarian F, Zhou Z, Olsen RE, Sperstad S, Ringø E. (2012) Culturable autochthonous gut bacteria in Atlantic salmon (Salmo salar L.) fed diets with or without chitin. Characterization by 16S rRNA gene sequencing, ability to produce enzymes and in vitro growth inhibition of four fish pathogens. Aquaculture. 1, 326-329.

Atarashi K, Tanoue T, Shima T, Imaoka A, Kuwahara T, Momose Y. (2011) Induction of colonic regulatory T cells by indigenous Clostridium species. Science. 331, 337-341. doi: 10.1126/ science.1198469

Avila FA, Paulillo AC, Schocken-Iturrino RP, Lucas FA, Orgaz A, Quintana JL. (1995) A comparative study of the efficiency of a probiotic and the anti-K99 and anti-A14 vaccines in the control of diarrhea in calves in Brazil. Rev Elev Med Vet Pays Trop. 48, 239-243

Azad E., Rico DE, Derakhshani H, Havartine KJ, Khafipour E. (2015) Composition of rumen microbiota alters following diet-induced milk fat depression in dairy cows. Joint Annual Meeting of American Society of Animal Science and American Dairy Science Association, , July 12-16, Orlando-FL.

Azad MB, Konya T, Maughan H, Guttman DS, Field CJ, Sears MR, Becker AB, Scott JA, Kozyrskyj AL. (2013) Infant gut microbiota and the hygiene hypothesis of allergic disease: impact of household pets and siblings on microbiota composition and diversity. Allergy Asthma Clin Immunol. 9, 15. doi: 10.1186/1710-1492-9-15.

Balcázar JL, Lee NM, Pintado J, Planas M. (2010) Phylogenetic characterization and in situ detection of bacterial communities associated with seahorses (Hippocampus guttulatus) in captivity. Syst Appl Microbiol. 33, 71-77. doi: 10.1016/j. syapm.2009.11.005

Benno Y, Nakao H, Uchida K, Mitsuoka T. (1992) Impact of the advances in age on the gastrointestinal microflora of beagle dogs. J. Vet. Med. Sci. 54, 703-706.

Benyacoub J, Czarnecki-Maulden GL, Cavadini C, Sauthier T, Anderson RE, Schiffrin EJ, von der Weid T. (2003) Supplementation of food with Enterococcus faecium (SF68) stimulates immune functions in young dogs. J Nutr. 133, 1158-1162.

Bybee SN, Scorza AV, Lappin MR. (2011) Effect of the probiotic Enterococcus faecium SF68 on presence of diarrhea in cats and dogs housed in an animal shelter. J Vet Intern Med. 25, 856-860. doi: 10.1111/j.1939-1676.2011.0738.x.

Collado MC, Grześkowiak $七$, Salminen S. (2007) Probiotic strains and their combination inhibit in vitro adhesion of pathogens to pig intestinal mucosa. Curr Microbiol. 55, 260-265. doi:10.1007/s00284-007-0144-8

Dar A, Singh S, Palod J, Ain K, Kumar N, Farooq F . (2017)Effect of Probiotic, Prebiotic and Synbiotic on Hematological Parameters of Crossbred Calves. Int. J. Livest. Res. 7, 128-136.

De Menezes AB, Lewis E, O'Donovan M, O'Neill BF, Clipson N, Doyle EM. Microbiome analysis of dairy cows fed pasture or total mixed ration diets. FEMS Microbiol Ecol. 2011;78(2):256-265. doi:10.1111/j.1574-6941.2011.01151.x
De Vadder F, Grasset E, Mannerås Holm L, Karsenty G, Macpherson AJ, Olofsson LE, Bäckhed F. (2018) Gut microbiota regulates maturation of the adult enteric nervous system via enteric serotonin networks. Proc Natl Acad Sci U S A. 19, 6458-6463. doi: 10.1073/pnas.1720017115.

De Vrese M, Schrezenmeir J. (2008) Probiotics, prebiotics, and synbiotics. Adv Biochem Eng Biotechnol. 111, 1-66. doi: 10.1007/10_2008_097

Derakhshani, H., J.C. Plaizier, and E. Khafipour. 2016. Udder microbiome in health and mastitis. ADSA, ASAS, and CSAS 2016 Joint Annual Meeting, July 19-23, Salt Lake City-UT.

Dhanasiri AK, Brunvold L, Brinchmann MF, Korsnes K, Bergh $\varnothing$, Kiron V. (2011) Changes in the intestinal microbiota of wild Atlantic cod Gadus morhua L. upon captive rearing. Microb Ecol. 61, 20-30. doi: 10.1007/s00248-010-9673-y.

Diaz Heijtz R, Wang S, Anuar F, Qian Y, Björkholm B, Samuelsson A, Hibberd ML, Forssberg H, Pettersson S. (2011) Normal gut microbiota modulates brain development and behavior. Proc Natl Acad Sci U S A. 108, 3047-3052. doi: 10.1073/ pnas. 1010529108.

Dibner JJ, Richards JD. (2005) Antibiotic growth promoters in agriculture history and mode of action. Poult Sci. 84, 634643. doi: 10.1093/ps/84.4.634

Dickerson F, Severance E, Yolken R. (2017) The microbiome, immunity, and schizophrenia and bipolar disorder. Brain Behav Immun. 62, 46-52. doi: 10.1016/j.bbi.2016.12.010.

Difford GF, Plichta DR, Løvendahl P, Lassen J, Noel SJ, Højberg O, Wright AG, Zhu Z, Kristensen L, Nielsen HB, Guldbrandtsen B, Sahana G. (2018) Host genetics and the rumen microbiome jointly associate with methane emissions in dairy cows. PLoS Genet. 14(10):e1007580. doi: 10.1371/journal.pgen.1007580.

Eckburg PB, Bik EM, Bernstein CN, Purdom E, Dethlefsen L, Sargent M, Gill SR, Nelson KE, Relman DA. (2005) Diversity of the Human Intestinal Microbial Flora. Science. 308, 1635-1638.

Erdoğmuş SZ, Gülmez N, Fındık A, Şah H, Gülmez M. (2019) Efficacy of probiotics on health status and growth performance of Eimeria tenella infected broiler chickens. Kafkas Univ Vet Fak Derg, 25, 311-320. doi: 10.9775/kvfd.2018.20889

Ericsson AC, Personett AR, Grobman ME, Rindt $H$, Reinero CR. (2016) Composition and Predicted Metabolic Capacity of Upper and Lower Airway Microbiota of Healthy Dogs in Relation to the Fecal Microbiota. PLoS One. 11, e0154646. doi: 10.1371/journal.pone.0154646.

Ezell JM, Wegienka G, Havstad S, Ownby DR, Johnson CC, Zoratti EM. (2013) Across-sectional analysis of pet-specific immunoglobulin E sensitization and allergic symptomatology and household pet keeping in a birth cohort population. Allergy Asthma Proc. 34, 504-510. doi: 10.2500/aap.2013.34.3698

FAO/WHO. (2002) Guidelines for the Evaluation of Probiotics in Food, Food Agric Organ United Nation World Health Organ, p. 2002. Working Group Report

Ferrer M, Méndez-García C, Rojo D, Barbas C, Moya A. (2017) Antibiotic use and microbiome function. Biochem Pharmacol. 134, 114-126. doi: 10.1016/j.bcp.2016.09.007

Firkins JL, Yu Z. (2015) Ruminant nutrition symposium: how to use data on the rumen microbiome to improve our understanding of ruminant nutrition. J Anim Sci. 93, 1450-1470. doi: 10.2527/jas.2014-8754.

Garcia-Mazcorro JF, Suchodolski JS, Jones KR, Clark-Price SC, Dowd SE, Minamoto Y, Markel M, Steiner JM, Dossin O. (2012) Effect of the proton pump inhibitor omeprazole on the gastrointestinal bacterial microbiota of healthy dogs. FEMS Microbiol Ecol. 80, 642-636. doi: 10.1111/j.1574-6941.2012.01331.x. 
Gong J, Si W, Forster RJ, Huang R, Yu H, Yin Y. (2007) 16s rRNA gene- based analysis of mucosa-associated bacterial community and phylogeny in the chicken gastrointestinal tracts: From crops to ceca. FEMS Microbiol Ecol. 59, 147-157. doi: 10.1111/j.1574-6941.2006.00193.x

Grześkowiak Ł, Endo A, Beasley S, Salminen S. (2015) Microbiota and probiotics in canine and feline welfare. Anaerobe. 34, 1423. doi: 10.1016/j.anaerobe.2015.04.002.

Henderson G, Cox F, Ganesh S, Jonker A, Young W, Janssen PH. (2015) Rumen microbial community composition varies with diet and host, but a core microbiome is found across a wide geographical range. Sci. Rep. 5, 14567.

Hesselmar B, Aberg N, Aberg B, Eriksson B, Bjorksten B. (1999) Does early exposure to cat or dog protect against later allergy development?. Clin Exp Allergy. 29, 611-617.

Hilty M, Burke C, Pedro H, Cardenas P, Bush A, Bossley C, Davies J, Ervine A, Poulter L, Pachter L, Moffatt MF, Cookson WO. (2010) Disordered microbial communities in asthmatic airways. PLoS One. 5, e8578. doi: 10.1371/journal.pone.0008578.

Huang YJ, Nariya S, Harris JM, Lynch SV, Choy DF, Arron JR, Boushey H. (2015) The airway microbiome in patients with severe asthma: Associations with disease features and severity. J Allergy Clin Immunol. 136, 874-884. doi: 10.1016/j. jaci.2015.05.044.

Human Microbiome Project Consortium. (2012) Structure, function and diversity of the healthy human microbiome. Nature. 13, 207-214.

Ivanov II, Atarashi K, Manel N, Brodie EL, Shima T, Karaoz U. (2009) Induction of intestinal Th17 cells by segmented filamentous bacteria. Cell. 139, 485-498. doi: 10.1016/j.cell.2009.09.033

Jami E, Israel A, Kotser A, Mizrahi I. (2013) Exploring the bovine rumen bacterial community from birth to adulthood. ISME $J$. 7, 1069-1079. doi: 10.1038/ismej.2013.2.

Jatkauskas J, Vrotniakiene V. (2010) Effects of probiotic dietary supplementation on diarrhoea patterns, faecal microbiota and performance of early weaned calves. VET MED-CZECH. 55, 494-503.

Jenkins EK, Lee-Fowler TM, Angle TC, Behrend EN, Moore GE. (2016) Effects of oral administration of metronidazole and doxycycline on olfactory capabilities of explosives detection dogs. Am J Vet Res. 77, 906-912. doi: 10.2460/ajvr.77.8.906

Jernberg C, Löfmark S, Edlund C, Jansson JK. (2007) Long-term ecological impacts of antibiotic administration on the human intestinal microbiota. ISME J. 1, 56-66.

Jeurissen SH, Lewis F, Van der Klis JD, Mroz Z, Rebel JM, Ter Huurne AA. (2002) Parameters and techniques to determine intestinal health of poultry as constituted by immunity, integrity, and functionality. Curr Issues Intest Microbiol. 3, 1-14.

Jewell KA, McCormick CA, Odt CL, Weimer PJ, Suen G. (2015) Ruminal Bacterial Community Composition in Dairy Cows Is Dynamic over the Course of Two Lactations and Correlates with Feed Efficiency. Appl Environ Microbiol. 81, 4697-4710. doi: 10.1128/AEM.00720-15

Kempf C, Schulz B, Strauch C. (2010) Virusnachweis in Kotproben und klinische sowie labordiagnostische Befunde von Hunden mit akutem haemorrhagischem Durchfall. Tieraerztliche Praxis. 38, 79-86.

Khafipour E, Krause DO, Plaizier JC. (2009) A grain-based subacute ruminal acidosis challenge causes translocation of lipopolysaccharide and triggers inflammation. J. Dairy Sci. 92, 1060-1070. doi: 10.3168/jds.2008-1389

Kieler IN, Shamzir Kamal S, Vitger AD, Nielsen DS, Lauridsen C, Bjornvad CR. (2017) Gut microbiota composition may relate to weight loss rate in obese pet dogs. Vet Med Sci. 3, 252-262. doi: $10.1002 / v m s 3.80$

Krause DO, Nagaraja TG, Wright AD, Callaway TR. (2013) Board-invited review: Rumen microbiology: Leading the way in microbial ecology. J. Anim. Sci. 91, 331-341. doi: 10.2527/ jas.2012-5567.

Krogh HV, Kristensen S. (1976) A study of skin diseases in dogs and cats. II. Microflora of the normal skin of dogs and cats. Nord Vet Med. 28, 459-463.

Kumar S, Chen C, Indugu N, Werlang GO, Singh M, Kim WK, Thippareddi $H$. (2018) Effect of antibiotic withdrawal in feed on chicken gut microbial dynamics, immunity, growth performance and prevalence of foodborne pathogens. PLoS One. 13, 2 :e0192450. doi: 10.1371/journal.pone.0192450.

Ladirat SE, Schols HA, Nauta A, Schoterman MH, Keijser BJ, Montijn RC, Gruppen H, Schuren FH. (2013) High-throughput analysis of the impact of antibiotics on the human intestinal microbiota composition. J Microbiol Methods. 92, 387-397. doi: 10.1016/j.mimet.2012.12.011.

Lauber CL, Hamady M, Knight R, Fierer N. (2009) Pyrosequencing-based assessment of soil $\mathrm{pH}$ as a predictor of soil bacterial community structure at the continental scale. Appl Environ Microbiol. 75, 5111-5120. doi: 10.1128/AEM.00335-09.

Ley RE, Hamady M, Lozupone C, Turnbaugh PJ, Ramey RR, Bircher JS, Schlegel ML, Tucker TA, Schrenzel MD, Knight R, Gordon JI. (2008) Evolution of mammals and their gut microbes. Science 320, 1647-1651. doi: 10.1126/science. 1155725.

Li F, Guan LL. (2017) Metatranscriptomic Profiling Reveals Linkages between the Active Rumen Microbiome and Feed Efficiency in Beef Cattle. Appl Environ Microbiol. 17, 83(9):e00061-17. doi: 10.1128/AEM.00061-17.

Li X, Yu Y, Feng W, Yan Q, Gong Y. (2012) Host species as a strong determinant of the intestinal microbiota of fish larvae. J Microbiol. 50, 29-37. doi: 10.1007/s12275-012-1340-1.

Litonjua AA, Milton DK, Celedon JC, Ryan L, Weiss ST, Gold DR. (2002) A longitudinal analysis of wheezing in young children: the independent effects of early life exposure to house dust endotoxin, allergens, and pets. J Allergy Clin Immunol. 110, 736-742.

Lippi I, Perondi F, Ceccherini G, Marchetti V, Guidi G. (2017) Effects of probiotic VSL\#3 on glomerular filtration rate in dogs affected by chronic kidney disease: A pilot study. Can Vet J. Dec;58(12):1301-1305.

Lodge CJ, Allen KJ, Lowe AJ, Hill DJ, Hosking CS, Abramson MJ, Dharmage SC. (2012) Perinatal cat and dog exposure and the risk of asthma and allergy in the urban environment: a systematic review of longitudinal studies. Clin Dev Immunol. 2012, 176484.

Maki JJ, Klima CL, Sylte MJ, Looft T. (2019) The Microbial Pecking Order: Utilization of Intestinal Microbiota for Poultry Health. Microorganisms. 20, 7. doi: 10.3390/microorganisms7100376

Marcináková M, Simonová M, Strompfová V, Lauková A. (2006) Oral application of Enterococcus faecium strain EE3 in healthy dogs. Folia Microbiol (Praha). 51, 239-242. doi:10.1007/ BF02932129

Marri PR, Stern DA, Wright AL, Billheimer D, Martinez FD. (2013) Asthma-associated differences in microbial composition of induced sputum. J Allergy Clin Immunol. 131, 346-352. doi: 10.1016/j.jaci.2012.11.013.

McCain S, Allender MC, Schumacher J, Ramsay E. (2011) The effects of a probiotic on blood urea nitrogen and creatinine concentrations in large felids. J Zoo Wildl Med. 42, 426-429. doi: 10.1638/2010-0235.1. 
Mochizuki M, Hashimoto M, Ishida T. (2001) Recent epidemiological status of canine viral enteric infections and Giardia infection in Japan. J Vet Med Sci. 63, 573-575.

Montoya-Alonso JA, Bautista-Castano I, Pena C, Suarez L, Juste MC, Tvarijonaviciute A. (2017) Prevalence of canine obesity, obesity-related metabolic dysfunction, and relationship with owner obesity in an obesogenic region of Spain. Front Vet Sci. 4:59. doi: 10.3389/fvets.2017.00059

Neal-McKinney JM, Lu X, Duong T, Larson CL, Call DR, Shah DH, Konkel ME. (2012) Production of organic acids by probiotic lactobacilli can be used to reduce pathogen load in poultry. PLoS One. 7(9):e43928. doi: 10.1371/journal.pone.0043928.

Nermes M, Niinivirta K, Nylund L, Laitinen K, Matomaki J, Salminen S, Isolauri E. (2013) Perinatal pet exposure, faecal microbiota, and wheezy bronchitis: is there a connection?. ISRN Allergy. 2013, 827934. doi: 10.1155/2013/827934.

Olchowy TWJ, Soust M, Alawneh J. (2019) The effect of a commercial probiotic product on the milk quality of dairy cows. $J$ Dairy Sci. 102, 2188-2195. doi:10.3168/jds.2018-15411

O'Mahony SM, Clarke G, Borre YE, Dinan TG, Cryan JF. (2015) Serotonin, tryptophan metabolismand the brain-gut-microbiome axis. Behav Brain Res. 277, 32-48. doi: 10.1016/j. bbr.2014.07.027

Ownby DR, Johnson CC, Peterson EL. (2002) Exposure to dogs and cats in the first year of life and risk of allergic sensitization at 6 to 7 years of age. JAMA. 288, 963-972.

Panda S, El khader I, Casellas F, López Vivancos J, García Cors M, Santiago A, Cuenca S, Guarner F, Manichanh C. (2014) Shortterm effect of antibiotics on human gut microbiota. PLoS One. 9, e95476. doi: 10.1371/journal.pone.0095476.

Paz HA, Anderson CL, Muller MJ, Kononoff PJ, Fernando SC. (2016) Rumen Bacterial Community Composition in Holstein and Jersey Cows Is Different under Same Dietary Condition and Is Not Affected by Sampling Method. Front Microbiol. 7, 1206. doi: 10.3389/fmicb.2016.01206.

Peterson J, Garges S, Giovanni M, McInnes P, Wang L, Schloss JA. (2009) The NIH Human Microbiome Project. Genome Res. 19, 2317-2323.

Pilla R, Suchodolski JS. (2020) The Role of the Canine Gut Microbiome and Metabolome in Health and Gastrointestinal Disease. Front Vet Sci. 14, 98. doi:10.3389/fvets.2019.00498.

Plaizier JC, Krause DO, Gozho GN, McBride BW. (2008) Subacute ruminal acidosis in dairy cows: The physiological causes, incidence and consequences. Vet J. 176, 21-31. doi: 10.1016/j. tvjl.2007.12.016

Plaizier, JC, Li S, Tun HM, Krause DO, Khafipour E. (2017) Effects of experimentally induced subacute ruminal acidosis (SARA) on the rumen and hindgut microbiome in dairy cows. Front. Microbiol. Jan 25, 2128.

Ratre P, Singh RR, Chaudhary SS, Chaturvedani AK, Pavel VR, Hanumant D. (2019) Effect of prebiotic and probiotic supplementation on growth performance and body measurement in pre- ruminant Surti buffalo calves. J. Pharm. Innov. 8, 265269.

Rehman HU, Vahjen W, Awad WA, Zentek J. (2007) Indigenous bacteria and bacterial metabolic products in the gastrointestinal tract of broiler chickens. Arch AnimNutrit. 61:319-35. doi: 10.1080/17450390701556817

Rochus K, Janssens GP, Hesta M. (2014) Dietary fibre and the importance of the gut microbiota in feline nutrition: a review. Nutr Res Rev. 27, 295-307. doi:10.1017/S0954422414000213

Rodrigues DR, Wilson KM, Trombetta M, Briggs WN, Duff AF, Chasser KM, Bottje WG, Bielke L. (2020) A Proteomic View of the Cross-Talk Between Early Intestinal Microbiota and
Poultry Immune System. Front Physiol. 13, 11-20. doi:10.3389/ fphys.2020.00020.

Rodrigues Hoffmann A, Patterson AP, Diesel A, Lawhon SD, Ly HJ Elkins Stephenson C, Mansell J, Steiner JM, Dowd SE, Olivry T, Suchodolski JS. (2014) The skin microbiome in healthy and allergic dogs. PLoS One. 9, e83197

Rossi G, Pengo G, Caldin M, Palumbo Piccionello A, Steiner JM, Cohen ND, Jergens AE, Suchodolski JS. (2014) Comparison of microbiological, histological, and immunomodulatory parameters in response to treatment with either combination therapy with prednisone and metronidazole or probiotic VSL\#3 strains in dogs with idiopathic inflammatory bowel disease. PLoS One. 10, 9(4):e94699. doi: 10.1371/journal. pone.0094699.

Russell JB, Rychlik JL. (2001) Factors that alter rumen microbial ecology. Science. 292, 1119-1122.

Sarowska J, Choroszy-Król I, Regulska-llow B, Frej-Mądrzak M, Jama-Kmiecik A. (2013) The therapeutic effect of probiotic bacteria on gastrointestinal diseases. Adv Clin Exp Med. 22, 759-766.

Schmidt M, Unterer S, Suchodolski JS, Honneffer JB, Guard BC Lidbury JA, Steiner JM, Fritz J, Kölle P. (2018) The fecal microbiome and metabolome differs between dogs fed Bones and Raw Food (BARF) diets and dogs fed commercial diets. PLoS One. 15;13(8):e0201279. doi: 10.1371/journal.pone.0201279.

Simpson JM, Martineau B, Jones WE, Ballam JM, Mackie RI. (2002) Characterization of fecal bacterial populations in canines: effects of age, breed and dietary fiber. Microb Ecol. 44,186-197

Song SJ, Lauber C, Costello EK, Lozupone CA, Humphrey G, Berg-Lyons D,Caporaso JG, Knights D, Clemente JC, Nakielny S, Gordon Jl, Fierer N, Knight R. (2013) Cohabiting family members share microbiota with one another and with their dogs. Elife. 16, :e00458. doi: 10.7554/eLife.00458.

Strachan DP. (1989) Hay fever, hygiene, and household size. BMJ. 299,1259-1260. doi:10.1136/bmj.299.6710.1259

Strompfová V, Pogány Simonová $\mathrm{M}$, Gancarčíková $\mathrm{S}$, Mudroňová D, Farbáková J, Mad'ari A, Lauková A. (2014) Effect of Bifidobacterium animalis $B / 12$ administration in healthy dogs. Anaerobe. 28, 37-43. doi: 10.1016/j.anaerobe.2014.05.001.

Suchodolski JS, Camacho J, Steiner JM. (2008) Analysis of bacterial diversity in the canine duodenum, jejunum, ileum, and colon by comparative $16 \mathrm{~S}$ rRNA gene analysis. FEMS Microbiol Ecol. 66, 567-578. doi:10.1111/j.1574-6941.2008.00521.x

Suchodolski JS, Dowd SE, Westermarck E, Steiner JM, Wolcott RD Spillmann T, Harmoinen JA. (2009) The effect of the macrolide antibiotic tylosin on microbial diversity in the canine small intestine as demonstrated by massive parallel 16S rRNA gene sequencing. BMC Microbiol. 9, 210. doi: 10.1186/1471-21809-210.

Suchodolski JS, Olson E, Honneffer JB, Guard B, Blake A, AIShawaqfeh M, Steiner JM, Barr J, Gaschen F. (2016) Effects of a hydrolyzed protein diet and metronidazole on the fecal microbiome and metabolome in healthy dogs. J Vet Intern Med 30,1455 .

Suchodolski JS. (2011) Companion animals symposium: microbes and gastrointestinal health of dogs and cats. J Anim Sci. 89, 1520-1530. doi: 10.2527/jas.2010-3377

Summers SC, Quimby JM, Isaiah A, Suchodolski JS, Lunghofer PJ, Gustafson DL. (2019) The fecal microbiome and serum concentrations of indoxyl sulfate and $p$-cresol sulfate in cats with chronic kidney disease. J Vet Intern Med. 33, 662-669. doi:10.1111/jvim.15389

Swanson KS, Dowd SE, Suchodolski JS, Middelbos IS, Vester BM, Barry KA, Nelson KE, Torralba M, Henrissat B, Coutinho PM, 
Cann IK, White BA, Fahey GC Jr. (2011) Phylogenetic and gene-centric metagenomics of the canine intestinal microbiome reveals similarities with humans and mice. ISME J. 5, 639-649. doi: 10.1038/ismej.2010.162

Theis KR, Schmidt TM, Holekamp KE. (2012) Evidence for a bacterial mechanism for group-specific social odors among hyenas. Sci Rep. 2, 615

Tizard IR, Jones SW. (2018) The microbiota regulates immunity and immunologic diseases in dogs and cats. Vet Clin North Am Small Anim Pract. 48, 307-322. doi: 10.1016/j. cvsm.2017.10.008

Tomasello G, Mazzola M, Leone A, Sinagra E, Zummo G, Farina F, Damiani P, Cappello F, Gerges Geagea A, Jurjus A, Bou Assi T, Messina M, Carini (2016) Nutrition, Oxidative stress and intestinal dysbiosis: Influence of diet on gut microbiota in inflammatory bowel disease. Biomed Pap Med Fac Univ Palacky Olomouc Czech Repub. 160, 461-466. doi: 10.5507/ bp.2016.052.

van Bree FPJ, Bokken GCAM, Mineur R, Franssen F, Opsteegh M, van der Giessen JWB, Lipman LJA, Overgaauw PAM. (2018) Zoonotic bacteria and parasites found in raw meat-based diets for cats and dogs. Vet Rec. 182, 50. doi: 10.1136/ vr.104535

Vientós-Plotts Al, Ericsson AC, Rindt H, Grobman ME, Graham A, Bishop K, Cohn LA, Reinero CR. (2017) Dynamic changes of the respiratory microbiota and its relationship to fecal and blood microbiota in healthy young cats. PLoS One. 9, e0173818. doi: 10.1371/journal.pone.0173818.

Waite DW, Taylor MW. (2015) Exploring the avian gut microbiota: current trends and future directions. Front Microbiol. 3, 673. doi: 10.3389/fmicb.2015.00673.

Wei S, Morrison M, Yu Z. (2013) Bacterial census of poultry intestinal microbiome. Poult Sci Sympos. 92, 671-683. doi: 10.3382/ps.2012-02822

Wernimont S, Fritsch D, Jackson M, Badri D, Cochrane C, Gross K. (2019) Specialized Dietary Fibers Alter Microbiome Composi- tion \& Promote Fermentative Metabolism in the Lower Gastrointestinal Tract of Healthy Adult Cats (P20-045-19). Curr Dev Nutr. 3(Suppl 1). doi: 10.1093/cdn/nzz040.P20-045-19

Windschitl PM, Randall KM, Brainard DJ. (1991) Growth performance of Holstein dairy calves supplemented with a probiotic. Research progress report, 22

Winkler P, Ghadimi D, Schrezenmeir J, Kraehenbuhl JP. (2007) Molecular and cellular basis of microflora-host interactions. J Nutr. 137, 756-772. doi: 10.1093/jn/137.3.756S

Wold AE. (1998) The hygiene hypothesis revised: is the rising frequency of allergy due to changes in the intestinal flora? Allergy. 53, 20-25.

Wu J, Zhang Y, Yang H, Rao Y, Miao J, Lu X. (2016) Intestinal microbiota as an alternative therapeutic target for epilepsy. Can J Infect Dis Med Microbiol. 2016:9032809. doi: 10.1155/2016/9032809

Wu S, Wang G, Angert ER, Wang W, Li W, Zou H. (2012) Composition, diversity, and origin of the bacterial community in grass carp intestine. PLoS One.;7(2):e30440. doi: 10.1371/journal. pone.0030440.

Xenoulis PG, Palculict B, Allenspach K, Steiner JM, Van House AM, Suchodolski JS. (2008) Molecular-phylogenetic characterization of microbial communities imbalances in the small intestine of dogs with inflammatory bowel disease. FEMS Microbiol Ecol 66, 579-589. doi: 10.1111/j.1574-6941.2008.00556.x

Yegani M, Korver DR. (2008) Factors affecting intestinal health in poultry. Poult Sci. 87, 2052-2063. doi: 10.3382/ps.2008-00091

Yeoman CJ, Chia N, Jeraldo P, Sipos M, Goldenfeld ND, White BA. (2012) The microbiome of the chicken gastrointestinal tract. Anim Health Res Rev. 13, 89-99. doi: 10.1017/ S1466252312000138

Zitvogel L, Daillere R, Roberti MP, Routy B, Kroemer G. (2017) Anticancer effects of the microbiome and its products. Nat Rev Microbiol. 15, 465-478. doi: 10.1038/nrmicro.2017.44 